\title{
Measuring impact of systematic reviews using individual participant data: evidence from clinical guidelines
}

\author{
Claire Vale ${ }^{1}$, Larysa Rydzewska ${ }^{1 *}$, Lesley Stewart ${ }^{2}$, Maroeska Rovers ${ }^{3}$, Jonathan Emberson ${ }^{5}$, François Gueyffier ${ }^{4}$ \\ From 2nd Clinical Trials Methodology Conference: Methodology Matters \\ Edinburgh, UK. 18-19 November 2013
}

\section{Background}

Systematic reviews (SRs) using individual participant data (IPD) are often referred to as the gold standard due to improved precision and reliability. Furthermore, they may identify treatment by participant subgroup interactions, enabling better targeting of treatments. IPD SRs have enormous potential to influence clinical guidelines, however their uptake by guideline developers, as Level 1 evidence, is unclear.

\section{Objectives}

We aimed to assess the impact of IPD SRs of interventions on clinical guidelines across a variety of healthcare areas.

\section{Methods}

30 eligible IPD SRs published from 2008 to 2010 spanning clinical areas including cancer, cardiovascular disease, and epilepsy were identified from records of the Cochrane IPD Meta-analysis Methods Group. Clinical guidelines across corresponding healthcare areas, published or revised since 2010, were searched for references to these IPD SRs. Details of recommendations based on the results of these reviews and citations of other relevant SRs were collected.

\section{Results}

Searches identified 227 potentially relevant clinical guidelines. Preliminary results are based on four IPD SRs in cancer and 34 relevant guidelines. Each of the four IPD SRs was cited in 2 to 5 guidelines, however citations were only identified in 11/34 guidelines (32\%). Three of the 14 guidelines also cited aggregate data SRs, with little distinction between results of IPD or aggregate data SRs.

${ }^{1}$ MRC Clinical Trials Unit Hub for Trials Methodology Research, London, UK Full list of author information is available at the end of the article
Further results for all 30 IPD SRs and 227 guidelines will be presented.

\section{Conclusions}

Results of this study will help develop guidance regarding how best to use IPD SRs to inform guidelines and thus impact on clinical practice.

\section{Authors' details}

${ }^{1}$ MRC Clinical Trials Unit Hub for Trials Methodology Research, London, UK. ${ }^{2}$ Centre for Research and Dissemination, University of York, York, UK.

${ }^{3}$ The Radboud University Nijmegen Medical Centre, Nijmegen, The Netherlands. ${ }^{4}$ UMR5558, CNRC, University of Lyon, Lyon, France. ${ }^{5}$ Clinical Trial Service Unit and Epidemiological Studies Unit, Oxford, UK.

Published: 29 November 2013

\section{doi:10.1186/1745-6215-14-S1-P123}

Cite this article as: Vale et al:: Measuring impact of systematic reviews using individual participant data: evidence from clinical guidelines. Trials 2013 14(Suppl 1):P123.

Submit your next manuscript to BioMed Central and take full advantage of:

- Convenient online submission

- Thorough peer review

- No space constraints or color figure charges

- Immediate publication on acceptance

- Inclusion in PubMed, CAS, Scopus and Google Scholar

- Research which is freely available for redistribution 